\title{
REDES XAMÂNICAS, CURANDERISMO E PROCESSOS INTERÉTNICOS: UMA ANÁLISE COMPARATIVA $^{1}$
}

\author{
Esther Jean Langdon ${ }^{2}$
}

\begin{abstract}
Resumo
Este artigo examina os fatores históricos, sociais e demográficos que contribuíram para as mudanças dos papéis dos xamãs entre dois grupos indígenas da Colômbia. Os xamãs do vale do Sibundoy fortaleceram seu papel de cura durante o século XX por meio da articulação com as práticas terapêuticas da medicina popular conhecida como curanderismo. Entretanto, durante o mesmo período, os xamãs Siona, que habitam as terras baixas da Amazônia, perderam sua posição de líderes políticoreligiosos, e cessaram de praticar seus rituais durante duas décadas. Por meio desta comparação, argumenta-se que o xamanismo deve ser visto como um fenômeno constantemente em mudança, que emerge das interações entre fatores sociais, culturais, históricos e demográficos em situações específicas. 0 papel do xamã não é um fenômeno homogêneo, mas um que está em construção contínua, dependente da ação dos atores sociais em contextos particulares.
\end{abstract}

Palavras-chave: Xamanismo. Curanderismo. Sibundoy. Siona.

\footnotetext{
${ }^{1}$ Versão traduzida e revisada do artigo Interethnic Processes Affecting the Survival of Shamans: A Comparative Analysis, publicado em PINZÓN, Carlos Ernesto e SUÁREZ P, Rosa (orgs.) Otra America en Construcción: Medicinas Tradicionales, Religiones Populares. Bogota: Instituto Colombiano de Antropología e Instituto Colombiano de Cultura, 1991, p. 44-65. Memorias del Simpósio Identidad Cultural, Medicina Tradicional y Religiones Populares. 460 Congreso Internacional de Americanistas. Texto traduzido do inglês por Guilherme Mäder.

2 Professora Titular do Departamento de Antropologia e do Programa de Pós-Graduação em Antropologia da Universidade Federal de Santa Catarina, Brasil. estherjeanbr@yahoo.com.br
} 


\title{
SHAMANIC NETWORKS, CURANDERISMO AND INTERETHNIC PROCESSES: A COMPARATIVE ANALYSIS
}

\begin{abstract}
This article examines the historical, social and demographic factors that contributed to the changing roles of shamans among two indigenous groups of Colombia. The shamans of the Valley of Sibundoy strengthened their healing role during the 20TH century through articulation with popular medical practices known as curanderismo. However, during this same period, the Siona shamans, located in the Amazonian lowlands, lost their position as religious-political leaders and ceased to practice their rituals for two decades. Through this comparison, it is argued that shamanism should be seen as a constantly changing phenomenon that emerges out of the interplay of social, cultural, historical and demographic factors in specific situations. The role of the shaman is not a homogeneous phenomenon, but one that is in continuous construction depending upon social actors in particular contexts.
\end{abstract}

Keywords: Shamanism. Curanderismo. Sibundoy. Siona.

\section{INTRODUÇÃO}

$\mathrm{N}$ a Colômbia, a medicina popular é uma síntese de técnicas e saberes oriundos de vários grupos étnicos e períodos históricos do país. Os negros, os índios, os espanhóis, e muitos outros grupos contribuíram todos para a dinâmica das práticas médicas populares. Dentro desse sistema, a posição dos curandeiros indígenas é uma inversão do status normal que os índios tradicionalmente tiveram na sociedade colombiana. 0 índio frequentemente sofreu com o baixo status, o preconceito, e a falta de poder. No entanto, dentro do sistema médico popular conhecido como curanderismo, os curandeiros indígenas e suas técnicas representam uma importante fonte de poder. Alguns autores argumentaram que as noções acerca das doenças e de suas causas no curanderismo, um fenômeno principalmente mestiço, têm raízes nos substratos indígenas do país. Redes xamânicas, que existiram desde tempos pré-históricos, são importantes nesse sistema de medicina popular. Xamãs Sibundoy da Colômbia meridional podem ser vistos vendendo suas substâncias medicinais nos mercados populares das grandes cidades.

Neste artigo, examino a articulação entre índios e não-índios nas práticas médicas populares colombianas a partir de um ponto de vista histórico. Dedico 
este estudo a Valentin, que contribuiu para os estudos sobre práticas médicas e as noções de pessoa, saúde e corpo entre os caboclos amazônicos. Em 2003, ele publicou um importante artigo que relacionava a categoria de "engerar" das populações ribeirinhas do Tapajós com o perspectivismo da cosmologia xamânica indígena (WAWZYNIAK, 2003).

Meu objetivo aqui não é discutir o xamanismo da maneira como ele opera dentro do sistema do curanderismo. Essa tarefa foi empreendida por muitos outros (GARAY, 2005; PINZÓN, 1992; PINZÓN; SUÁREZ; RAMÍREZ DE JARA, 1997; RAMÍREZ DE JARA; TAUSSIG, 1987; URREA; ZAPATA, 1995). Pretendo explorar o processo de contato interétnico entre as etnias Sibundoy e Siona e os fatores que encorajaram ou desencorajaram seus xamãs a responderem à demanda por seus serviços nos mercados de medicina popular em outras partes da Colômbia durante a última metade do século XX. Neste período, os curacas Sibundoy se tornaram conhecidos por suas viagens às cordilheiras andinas, onde eles curavam doenças como bruxaria, má sorte, susto, e outros infortúnios. Porém, os xamãs Siona do baixo Putumayo, historicamente conhecidos por seus poderes, sofreram um considerável declínio, e os jovens deixaram de passar pelo treinamento xamânico por algumas décadas. Enquanto o xamanismo Sibundoy floresceu na rede do curanderismo, os xamãs Siona deixaram de atuar por duas décadas, e foi devido a outros interesses que suas práticas foram revitalizadas nos anos de 1990. Ainda que não se articulassem com a rede de medicina popular nos anos 1970 e 1980, os Siona responderam positivamente ao novo contexto, fazendo parte de uma rede xamânica da região amazônica que se articula com os profissionais urbanos nas "tomas de yajê" nas cidades do planalto (CAICEDO, 2007, 2009; LANGDON, 2010).

Os fatores que analisarei são de uma natureza coletiva, isto é, são aqueles comuns à comunidade como um todo, e não de uma natureza psicológica individual que explique os motivos de um xamã em particular. Meu foco está voltado para as décadas de 1970 e 1980, um período em que conduzi diversas pesquisas no departamento de Putumayo, na Colômbia meridional. Durante esse período, os xamãs Sibundoy desempenhavam um importante papel no curanderismo, ao passo que a situação dos Siona era caracterizada como uma de xamanismo sem xamãs. Ainda que os Siona adultos possuíssem conhecimento xamânico, nenhum deles se sentia apto a realizar os rituais xamânicos centrais, baseados na ingestão de yajé (ayahuasca), e nenhum jovem era motivado a passar por 
um aprendizado xamânico. As diferentes respostas dos xamãs desses dois grupos ante o crescente contato com a sociedade envolvente devem ser entendidas como resultado de fatores que influenciaram sua relação com a sociedade envolvente durante as sete primeiras décadas do século XX.

Uma interpretação comum para o ocaso dos xamãs e das práticas de medicina tradicional é o fracasso destes em competir com a eficácia superior da biomedicina (FOSTER; ANDERSON, 1978; LANDY, 1974). No entanto, pesquisas sobre medicina popular e seus especialistas terapêuticos demonstram que sistemas médicos tradicionais são continuamente criados e recriados. Espero demonstrar que este também é o caso dos xamanismos indígenas. Concentrar-me-ei sobre os fatores sociais, culturais, demográficos e históricos do contato interétnico que condicionam as possibilidades e as oportunidades de práticas xamânicas emergentes.

\section{Cura INDÍGENA NA COLÔMBIA MERIDIONAL}

Apesar de algumas diferenças entre as práticas de cura indígenas dos Sibundoy e dos Siona serem discutidas mais adiante, pode-se falar, em termos gerais, de um sistema regional na Colômbia meridional que se fundamenta nas práticas xamânicas e no uso de alucinógenos entre os grupos da bacia amazônica, como os Quéchua, os Kofan, e os grupos Tukano ocidentais, incluindo os Siona, os Makaguaje e os Coreguaje. Seus conceitos e métodos etiológicos de diagnóstico e cura são similares, e o xamã é definido como mediador com o mundo invisível. Seu poder de adivinhar as causas das doenças, assim como os eventos passados e futuros, é obtido por meio da ingestão de yajé, uma bebida psicoativa derivada principalmente da trepadeira Banisteriopsis sp. Nem todas as doenças são atribuídas a causas sobrenaturais, como feitiçaria ou ataques por espíritos, mas aquelas doenças que não respondem a tratamentos habituais com ervas ou drogas biomédicas, que se caracterizam por uma crise súbita ou sintomas incomuns, ou que são mais graves, são suspeitas de terem uma causa que só pode ser diagnosticada e combatida por um xamã, realizando a cerimônia do yajé. Uma vez que se suspeitou de causas sobrenaturais, procurar-se-á um xamã. Realiza-se uma cerimônia com o paciente e os membros da família presentes. Em seguida, o xamã contará o que descobriu em suas viagens pelo mundo dos espíritos, dará um prognóstico e receitará um tratamento que visa curar os sintomas da doença. 
0 xamã pode aplicar tal tratamento, ou o paciente pode procurar algum outro recurso, incluindo terapias da medicina científica ou popular.

0 conhecimento xamânico é obtido por meio de um treinamento intensivo com um mestre. 0 propósito desse treinamento é adquirir conhecimento e poder para viajar pelos reinos invisíveis, enquanto tomam yajé, contatar e barganhar com as entidades que influenciam os eventos da vida quotidiana. Essas viagens são consideradas perigosas, já que espíritos malignos podem atacar alguém que esteja sob a influência da substância. Acredita-se que se um mestre-xamã não está lá para proteger os outros que estão ingerindo yajé, uma pessoa "capturada" pelos espíritos pode nunca voltar a esta realidade, ou pode vir a cair fatalmente doente.

Uma vez que um aprendiz tenha acumulado conhecimento suficiente no uso do yajé e seja considerado forte o bastante para guiar e proteger os outros nos rituais, ele é considerado um mestre-xamã, e conduzirá suas próprias cerimônias. Entretanto, os xamãs nunca deixam de experimentar e aprender mais sobre os mundos invisíveis, visitando outros xamãs considerados mais experientes em algumas áreas como a cura, domínios específicos do universo e outros espíritos. Considera-se que os xamãs possuem diferentes quantidades de poder, e há frequentemente uma grande competição entre eles para obter mais poder e destruir o poder de um rival por meio da feitiçaria.

Também é possível perder poder e conhecimentos e, assim, ser reduzido a um homem comum. Essa perda de poder é sugerida quando um xamã experiencia, por si mesmo, visões ruins, ou quando ele não é mais capaz de enxergar os espíritos e visões que ele deseja ver. Na maior parte das vezes, a perda de poder é atribuída às práticas de feitiçaria de um xamã rival. Assim, a manutenção do status de xamã nunca é garantida, para nenhum indivíduo.

Qualquer doença pode ter várias causas, tanto naturais quanto místicas. Para a maioria das doenças, o processo de tratamento começa utilizando-se ervas e outras substâncias conhecidas e disponíveis aos membros da casa. 0 xamã não tem monopólio sobre tais formas de tratamento. Consequentemente, as doenças são primeiramente tratadas pelos membros da casa, depois por alguns indivíduos que se considera terem mais conhecimentos, e, finalmente, por um xamã, se a doença não responder aos tratamentos, ou se tornar muito grave. 0 itinerário terapêutico pode incluir o uso de fármacos industrializados, ou a procura de curandeiros não indígenas e/ou os serviços de saúde oficiais. A incorporação desses recursos alternativos de tratamento depende principalmente da acessibilidade, do 
cūsto, è da fāmiliaridade com o terapeuta ou o tratamento. Os próprios xamãs recomendam tais práticas para o tratamento dos sintomas físicos de uma doença. Todavia, se suspeitarem de alguma causa invisível que não permita a cura da doença via as terapias convencionais, a cerimônia xamânica deve ser realizada para combatê-la.

\section{Medicina POPUlar COLOMBIANA}

A medicina popular colombiana não pode ser considerada um sistema médico unificado caracterizado por um tipo específico de papel de cura. Ela representa várias crenças, práticas e curandeiros, que provêm dos grupos étnicos que povoaram o país. Alguns curandeiros podem ser definidos como tradicionais, mas, como Press (1971) bem demonstrou, há diversos papéis de cura emergentes que se desenvolveram. Consequentemente encontra-se na Colômbia uma grande variedade de curandeiros e práticas de tratamento que refletem a heterogeneidade da sociedade. Como descrito por Taussig (1980) e Press (1971), substâncias e práticas de cura associadas a origens indígenas são consideradas superiores. Isso é particularmente verdadeiro para aquelas práticas atribuídas aos grupos amazônicos. Curandeiros variam dos "doutores" impessoais, quase científicos, em Bogotá, até os curandeiros locais que conhecem intimamente seus clientes, espíritas afro-colombianos, e figuras religiosas carismáticas.

A racionalidade etiológica da medicina popular vai além dos processos biológicos sobre o corpo e envolve um pensamento causal, que incorpora os processos sobrenaturais, ambientais, emocionais e pessoais que afetam o bemestar (LANGDON; MACLENNAN, 1979, p. 217). Assim, o clima, o trabalho duro, a tristeza, a inveja, o medo, a má sorte, "0 ar malevolente" e a feitiçaria podem produzir doenças. 0 tratamento das doenças é eclético e incorpora produtos farmacêuticos, medicina convencional, assim como ervas e rituais. Ele pode envolver uma variedade de curandeiros diferentes, refletindo o esquema conceitual mais amplo da medicina popular.

É comum que o itinerário terapêutico de uma doença inclua uma variedade de práticas durante a busca pela cura, incluindo recursos da biomedicina. Press (1969) descreveu esse padrão para Bogotá, e a minha experiência nas áreas rurais confirma o padrão que ele descreveu. Tanto índios quanto não índios usam os centros médicos patrocinados pelo governo, concomitantemente com tratamentos 
indígenas e populares. Como Press aponta, problemas como pobreza, subnutrição e nível geral de saúde tornam difícil algum sistema terapêutico ser percebido como tendo consistentemente mais sucesso que outras formas. Ademais, quando se utilizam várias formas de tratamento, o que se percebe como efetivo depende da interpretação subjetiva e das condições sociais.

Na Colômbia meridional, as práticas da biomedicina introduzidas pelos missionários, pelas farmácias e pelos centros de saúde não ameaçam as práticas xamânicas indígenas. 0 conhecimento indígena se articulou com as práticas mestiças na região durante o século XX, resultando em um sistema conhecido como curanderismo. Quando examinado a partir da perspectiva das escolhas feitas nos itinerários terapêuticos por índios e mestiços afins, o curanderismo aparece de maneira mais significante que a biomedicina ocidental. Índios e não índios escolhem, em primeira instância, a partir de uma variedade de práticas que fazem parte do sistema popular heterogêneo, em vez de procurarem o centro de saúde ou o médico. Além disso, já que a maioria das drogas farmacêuticas pode ser vendida sem receita, recorre-se mais frequentemente à farmácia que ao centro de saúde, ainda que o custo das consultas em centros de saúde públicos seja ínfimo. As drogas ocidentais são frequentemente empregadas de acordo com percepções leigas ou populares, em vez daquelas baseadas na ciência farmacêutica.

Um sistema de intercâmbio envolvendo a troca de conhecimento xamânico existiu por séculos na Colômbia meridional. Este se originou na selva, onde os xamãs das terras baixas serviram de professores para os índios que vinham do vale Sibundoy. Os xamãs Sibundoy, por sua vez, levaram o conhecimento e as substâncias medicinais para as cidades no planalto. Chamados de curacas, os xamãs Sibundoy se encontram nos mercados de Pasto, Popayan e Cali, vendendo ervas e outras substâncias mágicas e medicinais. Eles também carregam consigo yajé preparado para realizar rituais de cura. Em sua descrição de práticas de cura em um bairro pobre de Popayan, Whiteford (1976, p. 102) afirma que "Os índios Sibundoy da Colômbia meridional também eram consultados, seja no mercado principal, seja quando eles faziam seus passeios periódicos pelo próprio bairro" (tradução nossa). Os moradores compram amuletos, ervas, cascos de tapir, bicos de tucano e pele de cobra. Em sua discussão sobre a relação entre os Sibundoy e os curandeiros da região, Whiteford (1976, p. 102) relata que "Em certo sentido, os Sibundoy são para o curandeiro o que o laboratório farmacêutico é para a farmácia" (tradução nossa). Taussig (1980) descreve rituais de yajé realizados 
por esses xamãs para os trabalhadores negros nos canaviais do Valle del Cauca, e Pinzón, Suárez e Garay (2005), Ramírez de Jara e Pinzón (1992) e Urrea e Zapata (1995) discutiram o importante papel dos xamãs Sibundoy no curanderismo.

Não índios também viajam para comunidades indígenas a procura de curandeiros. Durante minha estadia com os Sibundoy, presenciei um ritual de yajé realizado para um senhor de Bogotá que reclamava de um problema de pele crônico. Ele afirmou ter ido a muitos "doutores" em Bogotá, sem sucesso, e agora estava procurando os curacas Sibundoy. 0 curaca realizou o ritual de cura e, depois de muito dançar e cantar, um feitiço na forma de um pequeno embrulho de pano caiu no salão. Os objetos do embrulho foram examinados e diagnosticados como apetrechos usados para causar a doença. Os índios Siona me contaram sobre brancos, incluindo missionários, que buscaram a ajuda dos seus curacas na primeira metade do século XX, e eu presenciei tanto índios quanto mestiços participarem de práticas de curanderismo, nas quais os curacas combatiam feitiços, traziam boa sorte, achavam crianças perdidas e tentavam resolver vários outros infortúnios.

Consequentemente é difícil delimitar uma fronteira clara entre xamanismo e curanderismo; ambas as tradições partilham conceitos etiológicos similares, os mesmos pacientes e, amiúde, os mesmos métodos. Ademais, a medicina popular proporcionou uma oportunidade para os xamãs índios expandirem seu papel em um sistema em que para um curandeiro a identidade indígena é um importante capital simbólico.

\section{Os SIBUNDOY}

Os índios Sibundoy se localizam em um pequeno vale nas encostas orientais dos Andes a 2.200 metros acima do nível do mar. Como a estrada que conecta o planalto à bacia amazônica passa pelo vale, este foi historicamente um importante ponto mediador entre as terras baixas e o planalto.

Dois grupos indígenas, identificados como Sibundoy, tradicionalmente ocuparam o Vale: os Kamsa e os Ingano. Os Kamsa somavam aproximadamente 2.000 indivíduos nos anos 1970 (SEIJAS, 1971), e se localizam em pequenos sítios na área pantanosa do vale, separados dos outros moradores do lugar. Os Ingano, quéchua-falantes, vivem em dois dos quatro vilarejos, assim como em sítios ao 
longo do lado ocidental do vale. Uma população crescente de brancos habita 0 resto do vale e domina os maiores vilarejos e as atividades econômicas.

Os Sibundoy são um grupo de horticultores cujas culturas mais importantes são o milho e o feijão, ainda que o taro também seja importante. Alguns deles possuem gado, e a maioria cria galinhas, patos, e porquinhos-da-índia. Os índios formam um grupo étnico distinto, facilmente reconhecido, visto que mantêm sua língua nativa, moradia afastada e vestimentas tradicionais.

0 primeiro contato dos espanhóis com o vale Sibundoy foi em 1535 (CASTELLVÍ, 1941, p. 3). Os missionários dominicanos estavam presentes no vale desde o começo do século XVII, que, devido a sua localização, serviu de ligação entre exploradores, missionários e comerciantes que viajavam para a planície. Foi durante o final do século XIX que colonos de outras áreas começaram a se fixar ali, quando a estrada que vinha da cidade de Pasto foi concluída. Com o passar do tempo, aos poucos eles vieram a dominar, empurrando os Sibundoy para as terras pantanosas onde eles vivem agora.

A revisão dos dados populacionais de Seijas (1971) indica que a população dos Sibundoy cresceu de maneira significativa. 0 censo de 1711 registrou 320 Sibundoy. A população aumentou para 2.237 por volta de 1875 . Seijas atribui esse crescimento a uma dieta melhor, decorrente da introdução de porcos, vacas e utensílios de metal. Entre 1875 e 1918 a população diminuiu para 1.000, e desde então tem crescido continuamente. 0 declínio pode ser devido a conflitos com colonos que adentram a área, fatores naturais e emigração (SEIJAS, 1971). Nenhuma informação é fornecida a respeito de doenças.

Alguns aspectos do sistema médico Sibundoy foram estudados inicialmente pelo etnobotânico Melvin Bristol (1961) e a antropóloga Haydée Seijas (1969). Além dos seus curacas, os Sibundoy usam todos os recursos terapêuticos disponíveis para eles, incluindo médicos, farmacêuticos e curandeiros não índios. Como descrito acima, as doenças são primeiramente tratadas pelos membros da casa e, depois, por algum dos outros recursos médicos que estiverem ao alcance. Durante o meu estudo, as farmácias e um curandeiro mestiço foram os recursos mais comuns de auxílio médico fora da comunidade indígena. Antes de sua morte, nos anos 1960, um padre católico também foi procurado por suas práticas terapêuticas.

Por causa do extenso uso de recursos médicos não indígenas, concluímos que os processos diagnósticos e as noções etiológicas concernentes a causas não 
místicas de doenças refletiram uma influência notável da medicina popular (LANGDON; MACLENNAN, 1979, p. 219). A maioria das casas Sibundoy tinham aparelhos de rádio e as estações na região transmitiam frequentemente anúncios de medicamentos industrializados. 0 conteúdo de tais anúncios incluía os sintomas e as doenças que o remédio haveria de curar. As companhias farmacêuticas também distribuíam panfletos de propaganda no vale, listando sintomas, nomes de doenças e medicamentos alopáticos. Os Sibundoy os usavam para orientar suas compras de remédios e realizavam avalições criteriosas acerca da eficácia dos remédios comprados, baseados em sua própria experiência.

Apesar das ideias etiológicas dos Sibundoy concernentes a causas naturais serem similares àquelas relatadas pela medicina popular em outras partes do país (GUITIERREZ DE PINEDA, 1961), concepções sobre causas místicas eram mais particulares à cosmologia xamânica Sibundoy. Quando uma doença não respondia ao tratamento, ou manifestava sintomas incomuns, os Sibundoy procuravam o curaca, e este desempenhava um importante papel em relação a essas doenças, já que elas tendem a ser mais graves e causar maior preocupação. Outras formas de tratamento podem ser seguidas simultaneamente, mas o ritual xamânico era necessário para a cura completa. Também notamos que os curacas incorporaram a medicina ocidental em suas práticas (GREENE, 1998). Durante a minha pesquisa, um curaca Sibundoy pediu para conhecer o médico que trabalhava em meu projeto de pesquisa, a fim de trocar conhecimentos médicos.

0 tratamento por um xamã não é necessariamente menos caro que outras formas de tratamento, pois requer numerosos presentes como aguardente, cigarros e comida. É preciso aproximar-se do xamã respeitosamente, oferecendolhe aguardente antes de falar sobre o motivo da visita. A cerimônia, realizada pelo xamã com a família presente, deve incluir aguardente, comida e cigarros para todos. Alguns xamãs cobram taxas adicionais pela bebida alucinógena que eles fornecem. Alguns casos requerem mais do que uma cerimônia apenas.

No vale Sibundoy, o papel dos curacas é principalmente limitado a sua habilidade de curar ou de causar infortúnios por meio da feitiçaria. Assim, ele é temido ao mesmo tempo em que é respeitado. Seu papel não se estende para além do âmbito da cura, para as atividades políticas ou religiosas, como no caso dos xamãs das terras baixas. É possível que antes do contato com os espanhóis ele tivesse um papel mais abrangente, mas não existe documentação histórica ou etnográfica sugerindo isto. 


\section{Os SIONA}

Apesar dos índios Siona do noroeste da bacia amazônica terem sido contatados no início do século XVI, não muito depois dos Sibundoy, algumas características ecológicas e demográficas contribuíram para um processo de contato muito diferente. Em vez de serem confinados a uma área como o vale Sibundoy, eles viviam em malocas espalhadas ao longo do rio Putumayo e seus afluentes, que desemboca no rio Amazonas. Densas florestas subtropicais cobrem a terra, e o solo se torna duro e argiloso depois de limpo e cultivado por alguns anos. A subsistência se baseia na agricultura extensiva, combinada com a caça e a coleta.

Uma estimativa conservadora do número total de tukano-falantes ocidentais ao longo dos sistemas fluviais do Putumayo, do Caquetá e do Aguarico é de aproximadamente 8.000 (STEWARD, 1948, p. 738). Esses grupos falam dialetos aparentados, e fontes históricas indicam que pode ter havido até 3.000 falantes de siona ao longo do Putumayo no início do século XVIII, diminuindo para a casa dos 1.500 a 2.000 por volta do século XIX e para 1.000 por volta do começo do século XX (LANGDON, 1974, p. 32-34).

Estes grupos Tukano repeliram com sucesso as primeiras tropas espanholas que entraram na região, tirando vantagem de seu conhecimento superior sobre a região e sua habilidade de recuar para dentro da densa selva. Durante o século XVIII, missionários franciscanos estabeleceram vários postos avançados no rio. Eles agruparam os índios em povoados nucleares e estabeleceram rotas de comércio com o planalto. 0 comércio incluía cera, artesanato, ouro, milho, ovos de tartaruga, e outros produtos vegetais, que eram trocados na cidade de Pasto por roupas, utensílios de metal, e outros itens introduzidos pelos padres entre os índios. 0 principal objetivo dos missionários era civilizar, cristianizar e controlar os índios, acabando com a organização política da maloca, estabelecendo famílias monogâmicas, vestindo e batizando os índios. Ainda que eles tenham tido sucesso em perturbar a organização social indígena, as missões raramente duravam muito, e os Siona mantinham a integridade de suas práticas e valores culturais. As doenças obravam contra a empresa dos missionários. 0 agrupamento de índios em povoados nucleares levava frequentemente a uma rápida disseminação de doenças. Muitas vezes vilas inteiras foram varridas por uma única epidemia. Ademais, os próprios missionários sofriam com 0 ambiente tropical e muitos deles foram forçados a abandonar seus postos, ou morreram antes de fazê-lo. 
Eventualmente, os Siona se rebelavam e assassinavam seus senhores. As doenças tropicais, combinadas com os problemas de comunicação na selva isolada, contribuíram para uma história de contatos esporádicos entre brancos e índios, em vez de um contato contínuo como visto no vale Sibundoy.

Durante o século XIX, cessaram as atividades missionárias na planície, e os Siona foram deixados sós durante quase 100 anos, exceto por comerciantes ocasionais. Durante o final do século XIX, o contato com o mundo exterior voltou a crescer à medida que os produtos da selva, em especial a borracha, tornaram-se objeto de demanda na economia nacional. 0 início do ciclo da borracha começou por volta de 1900, e o retorno dos missionários marcou um novo período para os índios da região, o que levou a uma drástica redução da sua população e a perda do controle sobre seu território. Em 1920, os missionários fundaram uma escola missionária em Puerto Asis, um pequeno povoado localizado perto do sopé dos Andes, no rio Putumayo. As crianças Siona foram forçadas a entrar no internato, e uma vez mais a doença cobrou seu quinhão. A história oral narra os horrores na escola, quando o sarampo e outras doenças assolaram a missão e mataram uma grande parte das crianças. As doenças se espalharam rio acima e rio abaixo pelos povoados nativos, e, durante os anos 1920, comunidades Siona inteiras foram uma vez mais dizimadas. Em meados de 1920, a população Siona se reduziu para 300, um terço do que fora em 1900. Nos anos 1970, o número total de Siona era estimado em torno de 250 indivíduos. Novos dados indicam um aumento populacional desde a década de 1990 (GUARÍN; CURIEUX; CULLAR, 2003), possivelmente como resultado dos processos da reindigenização entre índios e colonos após da nova constituição colombiana (CHAVES-CHAMORRO, 2002, 2003) $)^{3}$.

Durante a primeira metade do século XX, o acesso à região era difícil, desencorajando qualquer grande migração de colonos. A região se tornou estratégica para os interesses nacionais, com as atividades de coleta de borracha e o conflito colombo-peruano nos anos 1930. Alguns jovens Siona serviram nas forças colombianas ao longo do Putumayo. Nos anos 1950, foi descoberto petróleo na região, e uma estrada ligando o planalto a Puerto Asis foi finalmente concluída nos anos 1960. Com a estrada, milhares de colonos do planalto afluíram para a selva. Eles praticamente cercaram as últimas comunidades Siona. Durante meu

\footnotetext{
${ }^{3}$ Numa viagem recente a Colômbia, uma liderança siona me indicou com grande orgulho que a população Siona no Putumayo já conta com 4000 membros.
} 
primeiro período de pesquisa, entre 1970 e 1974, Puerto Asis era uma movimentada cidade fronteiriça com umas 6.000 pessoas, e alguns colonos viviam ao longo do rio Putumayo, naquilo que fora o antigo território Siona. Metade dos Siona viviam em uma pequena reserva que se estendia por cinco quilômetros ao longo da margem do rio, quarenta e cinco quilômetros rio abaixo a partir de Puerto Asis. Os colonos habitavam em ambos os lados da reserva, e os Siona remanescentes viviam espalhados rio acima e rio abaixo, entremeados por colonos. Os Ingano das terras baixas do Equador e do Peru também viviam ao longo do rio.

Na primeira fase da minha pesquisa de campo, os Siona passavam por um processo de rápida transformação. Todos eram bilíngues, e as gerações mais jovens estavam abandonando o uso da língua nativa. Apenas alguns anciãos usavam vestimentas tradicionais, pois os Siona tentavam conscientemente parecer, pelo menos exteriormente, na vestimenta e na língua, com a população não índia a sua volta. Eles estavam bem cientes da sua posição marginalizada na sociedade colombiana e não desejavam serem identificados como índios quando negociavam em Puerto Asis. Em 1970, eles continuaram a viver de acordo com as técnicas tradicionais de subsistência, mas eles também estavam ganhando dinheiro com as colheitas que vendiam em Puerto Asis. Apesar de ainda serem semiautônomos economicamente, eles passaram a depender de muitos bens comerciais, incluindo roupas, potes e panelas, querosene para iluminação, aparelhos de rádio, etc. Apenas a dieta permaneceu basicamente autoproduzida.

Quando retornei à pesquisa de campo, em 1980, fiquei espantada com a rapidez das mudanças. Sua dependência do mercado econômico era quase total. A população de Puerto Asis aumentara para 30.000, e o número de residentes ao longo do rio crescera da mesma maneira. Agora, havia colonos em todos os arredores da pequena reserva Siona. Devido ao aumento da população, a caça e a pesca já não eram tão produtivas. Muitos homens Siona eram contratados como trabalhadores braçais para os colonos, ou estavam envolvidos em outras atividades rentáveis, e compravam uma grande parte de sua comida, assim como outros produtos. Viagens ao mercado eram muito mais frequentes do que no passado.

Uma revisão dos dados etnográficos e históricos indica que o papel do xamã foi um elemento chave na preservação dos Siona. A literatura histórica antiga que cobre os primeiros dois séculos de contato contém poucas referências ao xamã, aos rituais, ou ao sistema de cura. A literatura mais recente, que aborda os séculos XIX e XX, entretanto, fornece evidências concretas de que 0 
xamã desempenhava um papel chave na organização social Siona, como 0 cacique-curaca, ou líder político-religioso. Cada comunidade Siona estava alinhada com um mestre-xamã, que guiava os rituais comunais para o bemestar da comunidade. Os rituais eram realizados regularmente com membros da comunidade para assegurar boa caça e colheitas abundantes, para afastar os espíritos que trazem doenças e outros infortúnios, e para curar doenças graves que desafiam os tratamentos normais. 0 xamã, por meio desses rituais, era o protetor e o defensor da comunidade. Seu poder se estendia aos âmbitos político e social. Ele organizava atividades de trabalho comunal, reuniões festivas, e era encarregado de punir e repreender indivíduos cujas atividades inaceitáveis fossem socialmente perturbatórias. Durante as primeiras décadas desse século, os missionários e os oficiais colombianos reconheciam seu papel e esperavam que eles falassem pela comunidade e fizessem valer os desejos das autoridades.

Não é possível descobrir, a partir da literatura histórica, se esse papel era tão extenso antes da Conquista, e a história oral Siona sugere que o papel de cacique-curaca como descrito acima fosse talvez o resultado das tentativas dos franciscanos de controlar os índios (LANGDON, 1991). Sua história oral é bastante extensa e contém relatos que explicam os primeiros conflitos com as tropas espanholas, o primeiro padre que chegou à área, e eventos das várias missões estabelecidas durante os séculos XVII e XVIII. Tais histórias também falam das epidemias que assolaram as missões e, posteriormente, varreram dois terços da população remanescente, no começo do século XX.

Essas histórias são proveitosas, por sugerirem que o papel e o status do xamã foram fortalecidos como resultado do contato. Quando os espanhóis chegaram pela primeira vez, os Siona os repeliram em conflito aberto. De acordo com os Siona, os curacas então tomaram yajé e, vendo que os espanhóis estavam para retornar, decidiram lutar com seus poderes mágicos, e não com armas de fogo. Assim, o abandono de muitas das antigas primeiras missões é explicado pelo poder dos xamãs de invocarem os espíritos e causarem infortúnios aos missionários. Uma análise da história oral indica que os xamãs expandiram seu controle e seu poder sobre as comunidades Siona no processo de competição com os padres espanhóis pelo controle. Os xamãs também se apropriaram de algumas funções dos padres, aumentando seu status e prestígio. Os Siona frequentemente lembram que 0 xamã é para 0 índio o que o padre é para o homem branco, o indivíduo nomeado por Deus para controlar e proteger seu povo. Em tempos passados, 
os xamãs realizavam casamentos e outros rituais diretamente emprestados das cerimônias católicas. 0 yajé é bebido em um cálice de argila, supreendentemente parecido com o cálice da comunhão. Sonhos e visões induzidos pelo yajé também sugerem essa associação. Em uma visão que confirma o status de alguém como mestre-xamã, o novato viaja para a casa de Deus no reino celeste, onde Deus lhe dá o bastão de comando e lhe diz para cuidar e guiar seu povo. Nos sonhos, os xamãs aparecem frequentemente vestidos com trajes de padre. Assim, é possível que o poderoso papel do líder político-religioso encontrado no começo do século $\mathrm{XX}$ fosse o resultado da competição pelo controle sobre as comunidades Siona entre os antigos franciscanos e os xamãs. Nessa competição, o xamã saiu vitorioso, enquanto que os missionários não foram capazes de manter uma presença contínua ao longo do rio.

Conforme argumentei alhures (LANGDON, 1991), a performance dos rituais de yajé foi um mecanismo essencial para construir a cosmologia Siona. 0 papel do xamã de realizar os rituais foi importante na conservação dos mitos centrais do grupo. Através das visões induzidas pela performance do xamã, os participantes experienciam a complexa realidade invisível que jaz sob a perspectiva ordinária e que influencia todos os aspectos da vida quotidiana. As atividades de cura do xamã são apenas uma parte desse papel mais amplo.

A primeira ameaça que os xamãs enfrentaram durante esse século não foi da medicina ocidental, mas dos missionários que tramaram ativamente para solapar seu poder. Eles ganharam controle sobre as crianças, forçando-as a entrarem no internato desde os anos 1920 até os anos 1950, pregando contra os xamãs e suas atividades demoníacas, e desencorajando os jovens a treinarem para serem xamãs.

No passado, esperava-se que os homens jovens tentassem tornarem-se xamãs. 0 objetivo era desenvolver o conhecimento e o poder xamânicos, que os Siona chamavam de dau. Além de ser poder e conhecimento, acredita-se que 0 dau é uma substância que cresce no corpo de um indivíduo por meio de sucessivas ingestões de yajé. Quando suficiente, ele permite a um indivíduo deixar seu corpo e viajar. Se um indivíduo continuar tomando yajé, seu poder aumenta até que ele se torne um mestre-xamã.

0 dau é considerado uma substância delicada, que pode ser danificada por meio da feitiçaria ou da poluição causada pela menstruação, pela gravidez, ou pelo período pós-parto. Não são apenas as mulheres nesses estados que são 
contaminadas, mas também seus maridos. Durante a menstruação, as mulheres Siona se isolam em choupanas menstruais e vivem com seus maridos afastadas do povoado principal quando estão grávidas. 0 treinamento xamânico inclui longos períodos de isolamento na selva, longe de qualquer mulher. 0 sexo era proibido por um ou dois anos durante o aprendizado inicial.

Essas práticas culturais funcionavam para assegurar que o dau de um jovem aprendiz ou de um mestre-xamã não sofresse danos. Uma vez que tenha sofrido danos, o indivíduo perde seu poder e conhecimento, e deve começar a reconstruí-lo; porém, isso cada vez se torna mais difícil. Assim, o status de mestre-xamã não é garantido a todos que tentam alcançá-lo, e mestres-xamãs são aqueles poucos indivíduos que têm a força para constantemente enfrentar os perigos das viagens com yajé sem sucumbir ante os espíritos perigosos. A história oral aponta que a razão mais comum de um xamã perder seu poder é o feitiço de um xamã rival. As razões mais comuns relatadas a mim durante os anos 1970 que dificultaram a manutenção das práticas xamânicas eram a poluição originada pelo contato com os brancos, a incapacidade de manter o celibato depois de tantos anos de internato, ou o abandono dos costumes menstruais e de gravidez pelas mulheres Siona.

0 declínio dos xamãs Siona começou nos anos 1930, quando os jovens deixaram de treinar para se tornarem xamãs. 0 último mestre-xamã Siona no Putumayo morreu em meados dos anos 1960, e, com sua morte, nenhum dos anciãos remanescentes se sentia forte o suficiente para prosseguir com seu papel. Eles se reuniram algumas vezes para realizar o ritual, mas as experiências foram todas ruins. Vários anciãos que concluíram o treinamento xamânico continuaram a realizar alguns rituais de cura sem o uso do yajé. Um desses, irmão do xamã falecido, que tinha mais treinamento xamânico e de quem se esperava que assumisse o papel, não se sentiu confiante para guiar o grupo, por causa das várias más experiências durante os ritos do yajé. Ele não estava apto para se proteger a si mesmo, nem aos outros, dos perigos dos espíritos malignos que podem destruir qualquer ritual.

Quando esse indivíduo tinha seus setenta anos, ele retomou o treinamento com um xamã Kofan no rio San Miguel, por volta de 1975. Durante minha visita de 1980, ele falou sobre seu próximo período de treinamento e sua expectativa de receber dau suficiente para se tornar um mestre-xamã especializado em curar doenças. No entanto, a futilidade de seu sonho lhe parecia óbvia. A comunidade 
ao seu redor mudara demasiado para the prestar a honra e o respeito que lhe eram devidos. Ele não era procurado como guia, nem os homens e as mulheres mais jovens praticavam mais os costumes necessários para proteger seu dau. Mulheres grávidas e menstruadas não se mantinham mais em reclusão, e eu presenciei uma mulher grávida entrando na casa dele um dia, um ato impensável duas décadas atrás. Também, considerando-se a mudança na subsistência e na dieta, era-lhe impossível evitar a comida produzida pelos brancos, como arroz e feijão. Seu filho, que tinha a obrigação de lhe prover comida, plantava e caçava muito pouco por volta de 1980. Os membros da casa consumiam muita comida produzida por brancos, e essa comida fora explicitamente proibida pelo mestre Kofan. A liderança política da comunidade estava nas mãos do "governador", um oficial nomeado pelo Departamento de Assuntos Indígenas. A comunidade elegeu homens jovens para a vaga, aqueles que sabiam ler e escrever e estavam familiarizados com a sociedade branca. Não índios sempre andavam pela reserva e participavam da maioria das festividades da comunidade. Ele participava pouco das atividades sociais. Sua posição era de crescente isolamento, e, em vez de se dirigirem a ele com os termos de respeito apropriados a um homem de sua idade, com conhecimento xamânico, os membros da comunidade se referiam a ele jocosamente como "Padre Chucula", chamando-o pelo nome da bebida de banana-da-terra que é símbolo da sua dieta e da sua identidade indígena. Uma noite, depois de discutir suas esperanças para o próximo período de treinamento, ele observou, "Mas eu o perderei todo (o dau) quando eu voltar para cá, com essas mulheres que não mantêm mais os costumes e com todos os brancos que passam por minha casa hoje em dia". Ele morreu em 1985, sem realizar seu sonho de se tornar um mestre-xamã.

As cerimônias de yajé, importantes para a construção performativa da cosmologia Siona, não eram realizadas em benefício da comunidade desde a morte do último cacique-curaca nos anos sessenta, ainda que eles lamentassem constantemente a ausência dos seus próprios curacas e os procurassem entre outros grupos indígenas quando necessário. Nos casos de doenças sérias, eles faziam distinção entre o tratamento voltado para curar os sintomas e o tratamento voltado para combater a causa invisível. Para tratar os sintomas, eles empregavam ervas que eles conheciam, remédios populares que aprenderam com os colonos, curandeiros mestiços, farmácias, ou o centro médico em Puerto Asis. Para tratar ou combater as causas invisíveis da doença, eles procuravam curacas 
na rede regional, na ausência de xamãs Siona. Entretanto, certa desconfiança acompanhava o recurso a esses xamãs, que eram frequentemente acusados de práticas de feitiçaria e de causar mal aos Siona.

No final dos anos 1970, dois anciãos Siona retomaram seu treinamento xamânico. Ambos tiveram alguma experiência de aprendizagem quando jovens, mas a haviam interrompido devido a frequentes interações com brancos. Eles começaram a realizar rituais de yajé sem observar todos os tabus tradicionais e as prescrições requeridas por esses rituais. Membros de sua família, mestiços locais e visitantes das cidades andinas frequentemente participavam dos seus rituais, enquanto parte da comunidade Siona permanecia cética, alegando que os dois, na verdade, não sabiam o que estavam fazendo. Um dos irmãos morreu em 1979, e, durante minha visita em 1980, o outro me informou que ele não estava tomando yajé naquela época, por causa de duas noras grávidas que viviam em sua casa. Ele me informou que pretendia recomeçar depois que elas dessem à luz. Diferentemente de um xamã tradicional, esse ancião não exigia que as mulheres grávidas ou menstruadas se isolassem. Conquanto não seja o foco dessa análise histórica, esse Siona se tornou um xamã excepcionalmente importante nos anos 1990 até sua morte em 2007, em uma rede xamânica em que as elites das cidades urbanas procuravam os xamãs da selva amazônica para "tomas de yajê", motivadas por uma lógica e interesses diferentes daqueles por trás das redes da medicina popular.

\section{Conclusões}

Este artigo examinou o papel do xamã a partir de uma perspectiva histórica, na tentativa de entender os fatores em jogo no desenvolvimento do papel xamânico ao longo do tempo entre os índios Sibundoy e Siona. Na Colômbia meridional, o xamanismo é um traço distintivo que marca a identidade indígena. Embora todos os grupos partilhem uma cosmologia e práticas rituais similares, cada um vê seu sistema xamânico como distinto dos outros. A identidade étnica é marcada pelas variações de tabus e prescrições que pairam sobre o uso de alucinógenos, diferenças em experiências visionárias manifestadas em suas tradições orais e variações no cultivo e na preparação do yajé e de outras substâncias (LANGDON, 1981, 1986). Assim, por um lado, os Siona se distinguem a si mesmos dos Ingano, porque estes bebem aguardente nos rituais de yajé e suas mulheres não permanecem reclusas quando menstruadas ou grávidas. Eles distinguem sua tradição xamânica daquela 
dos Secoya (outro grupo Tukano), porque estes usam mais datura que yajé. Os Coreguajes são "outros" porque usam métodos e substâncias diferentes para a feitiçaria e seus curacas atacam seu próprio povo com mais frequência. Grupos distantes com os quais tinham contato mais raro eram acusados de praticarem mais atos de feitiçaria. Por outro lado, os Siona se identificam com os Kofan, a quem eles chamam de "amigos", pois eles observam os mesmos tabus e prescrições.

No processo de contato interétnico com os brancos, o xamanismo se tornou um traço distintivo que marca a identidade indígena dentro da rede de práticas xamânicas conhecida como curanderismo. Por causa do valor e do poder atribuídos às técnicas de cura indígenas, os xamãs Sibundoy expandiram suas práticas de cura e feitiçaria para além das suas próprias comunidades, em interação com clientes mestiços. Os xamãs Siona, a despeito de um papel político-religioso mais abrangente, resultante do colonialismo, passaram por um considerável hiato na atividade xamânica durante os anos 1970 e 1980, quando não havia aspirantes para preencher o papel de cacique-curaca. Os anciãos com conhecimento xamânico não estavam mais aptos para assumir a responsabilidade e não havia homens jovens que houvessem passado por aprendizagem suficiente.

Os fatores que contribuíram para o isolamento dos xamãs Siona e a articulação dos curacas Sibundoy no mercado da medicina popular são de natureza social, cultural, histórica, ecológica e demográfica, que tiveram uma influência nas relações interétnicas das quais emergiu o curanderismo.

Diferenças geográficas afetam a história de contato dos dois grupos. Os Sibundoy, vivendo em um vale localizado entre o planalto e as terras baixas, tiveram um contato mais constante e gradual com forasteiros ao longo dos últimos quinhentos anos. Os padres firmaram um controle mais bem sucedido sobre os Sibundoy por causa da sua proximidade e também por causa da circunscrição geográfica do Vale. A migração de colonos para a planície foi mais gradual que o rápido aumento do número de colonos na planície causado pela conclusão da rodovia nos anos 1960.

Ainda que o primeiro contato tenha causado um decréscimo populacional entre os Sibundoy, eles experienciaram um aumento da sua população desde o começo do século XVII e mantiveram uma comunidade homogênea e culturalmente resistente de 2.000 pessoas nos anos 1970. Os Siona, por sua vez, testemunharam drásticas reduções em sua população nos séculos XVII e XVIII, e então mais uma vez no começo do século XX, quando os pequenos bolsões de Siona 
em meio aos colonos tornaram a resistência cultural mais difícil. De 1900 a 1925, os Siona perderam 75\% de sua população por causa de epidemias, e a história oral Siona detalha o fim trágico e abrupto de três comunidades Siona, contando como os índios acabaram loucos pelas fortes febres e fugiram para a selva ou se afogaram no rio. É possível que a extrema desorganização social testemunhada por Neel et al. (1970) entre os Yanomami durante uma epidemia de sarampo tenha tido o mesmo efeito para os Siona durante esse período.

Fatores ecológicos também indicam diferenças. Embora os Sibundoy tenham sido capazes de manter padrões de subsistência tradicionais, aprimorados pela introdução de vacas e porcos, os padrões de subsistência na selva se alteraram mais significativamente devido ao desmatamento, e os Siona se tornam cada vez mais dependentes do mercado externo, com o abandono de vestimentas tradicionais, língua, festividades e rituais coletivos.

Em suma, por um lado, parece que o papel social dos curacas Sibundoy logrou mais estabilidade durante o século XX. Por outro lado, a organização social Siona, que estava centrada no cacique-curaca, foi significativamente alterada no mesmo século, especialmente depois de 1950, quando os efeitos cumulativos da violência, à época do retorno dos missionários, foram sentidos pela falta de novos aspirantes a xamã. Os missionários tiveram uma influência importante sobre os jovens Siona com o estabelecimento do internato. Mas, também se deve reconhecer que a interação com não índios foi sempre simbolicamente carregada de perigo para as práticas xamânicas. A ideologia, prescrições e tabus que funcionam para proteger o poder do xamã são incompatíveis com as relações com a sociedade envolvente. Enquanto os anciãos Siona expressavam frustração e resignação ante a impossibilidade de manter aspectos cruciais da "dieta" xamânica em face do crescente contato com os colonos, os Sibundoy não tiveram os mesmos problemas. A comida, o álcool e as práticas sanitárias dos brancos não representavam ameaça a sua performance xamânica. Na verdade, a aguardente foi incorporada ao ritual de yajéSibundoy, enquanto que os Siona alegavam que ela era nociva aos poderes xamânicos. Como Andrew Weil (apud LAMB, 1975, p. 11), frequentemente eu presenciei cerimônias de yajé entre os Sibundoy nas quais eu não podia determinar se o estado alterado do xamã se devia ao consumo em excesso de álcool ou à bebida psicoativa.

Este artigo demonstrou que o xamanismo deve ser visto como um fenômeno constantemente emergente, que surge em situações concretas a partir da interação 
de fatores sociais, culturais, históricos e demográficos. 0 papel do xamã não é um fenômeno homogêneo, mas um que está em construção contínua, dependente do contexto e de atores específicos. Além disso, a mudança no status e no papel do xamã não é resultado de uma competição com a biomedicina, mas das forças mais abrangentes que atuam nas relações interétnicas e dos valores atribuídos à identidade indígena.

\section{REFERÊNCIAS}

BRISTOL, Melvin L. The psychotropic banisteriopsis among the sibundoy of Colombia. Botanical Museum Leaflets, Cambridge, n. 21, p. 113-140, 1961.

CAICED0, F., Alhena. Neochamanismos y modernidad: lecturas sobre la emancipación. Revista Nómadas, Bogotá, n. 26, p. 114-147, 2007.

Nuevo chamanismos nueva era. Universitas Humanística, Bogotá, n. 68, p. 15-32, 2009.

CASTELLVÍ, P. Marcelino do. Reseña crítica sobre el descubrimiento de la región de Mocoa y fundaciones de la ciudad del mismo nombre. Amazonia Colombiana Americanista (Sibundoy), Colômbia, v. 4-5, n. 11, p. 1-20, 1941.

CHAVES-CHAMORRO, Margarita. Jerarquías de color y mestizaje en la Amazonia occidental colombiana. Revista Colombiana de Antropología, Bogotá, v. 38, p. 189-216, jan./dez. 2002.

. Cabildos multiétnicos e identidades depuradas. In: GARCIA, Clara Inés (Ed.). Fronteras territorios y metáforas. Medellín: Instituto de Estudios Regionales, INER, 2003. p. 121-135.

FOSTER, George; ANDERSON, Barbara. Medical anthropology. New York: Wiley. 1978.

GREENE, Shane. The shaman's needle: development, shamanic agency, and intermedicality in Aguaruna Lands, Peru. American Ethnologist, Arlington, v. 4, n. 25, p. 634-658, 1998.

GUITIERREZ DE PINEDA, Virginia. La medicina popular en Colombia: razones de su arraigo. Monografías Sociológicas, Bogotá, n. 8, 1961.

LANDY, David. Role adaptation: Traditional curers under the impact of western medicine. American Ethnologist, Arlington, n. 1, p. 103-127, 1974. 
LANGDON, E. Jean. Siona medical system: beliefs and behavior. New Orleans: Thesis, Tulane University, 1974.

. Cultural bases for trading of visions and spiritual knowledge in the colombian and ecuadorian montana. Networks of the Past: Regional Interaction in Archaeology. In: ANNUAL CONFERENCE OF THE ARCHAEOLOGY ASSOCIATION, 12., 1981, Calgary. Proceedings...Calgary: University of Calgary, 1981. p. 101-116.

. Las clasificaciones del yagé dentro del grupo Siona: etnobotánica, etnoquímica e historia. América Indígena, Brasília, v. 1, n. 46, p. 101-116, 1986.

. Poder y autoridad en el proceso político siona: desarrollo y muerte del shaman. In: EHRENREICH, Jeffrey (Org.). Antropologia política en el Ecuador. Quito: ABYA-YALA, 1991. p. 161-188.

. Xamãs e xamanismos: reflexões autobiográficas e intertextuais sobre a antropologia. Revista Ilha, Santa Catarina, v. 2, n. 11, p. 161-191, 2010.

LANGDON, E. Jean; MACLENNAN, Robert. Western biomedical and sibundoy diagnosis: an interdisciplinary comparison. Social Science and Medicine, Japan, n. 13B, p. 211-219, 1979.

LAMB, F. Bruce. Wizard of the Upper Amazon. Boston: Houghton Mifflin Co, 1975.

NEEL, James V. et al. Notes on the effect of measles and measles vaccine in a virginsoil population of south american indians. American Journal of Epidemiology, Oxford, v. 4, n. 91, p. 418-429, 1970.

PINZÓN, Carlos; SUÁREZ, Rosa; GARAY, Gloria. Mundos EN RED: la Cultura populaR frente a los retos del siglo XXI. Bogotá: Universidad Nacional de Colombia, 2005.

GUARÍN, Hugo Portela; CURIEUX, Tulio Rojas Enrique; CULLAR, Claudia Liliana Astaíza. Plano de vida del pueblo siona: ga'ntëya bain. Popayán: Taller Editorial Universidad del Cauca, 2003.

PRESS, Irwin. Urban illness: physicians, curers and dual use in Bogotá. Journal of Health and Social Behavior. Bogotá, n. 10, p. 209-17, 1969. 742-756, 1971.

The Urban Curandero. American Anthropologist, Arlington, n. 73, p.

RAMÍREZ DE JARA, María C.; PINZÓN, Carlos. Sibundoy shamanism and popular culture in Colombia. In: LANGDON, E. J.; BAER, G. (Ed.). Portals of power 
shamanism in south america. Albuquerque: University of New Mexico Press, 1992. p. 287-304.

RAMÍREZ DE JARA, María C. El chamanismo, un campo de articulación de colonizadores y colonizados en la región amazónica de Colombia. Revista Colombiana de Antropología, Colombia, n. 33, p. 165-184, 1997.

SEIJAS, Haydeé. Medical system of the sibundoy indians. 1969. Thesis (Doctoral) - Tulane University, New Orleans. 1969

SEIJAS, Haydeé. El crecimiento de población de los indios Sibundoy de Colombia a partir del siglo XVIII. In: INTERNATIONAL CONGRESS OF AMERICANISTAS, 39., 1971, Lima. Proceeding. .. Lima, 1971.

STEWARD, Julian H. Western Tucanoan. Handbook of South American Indians. Washington, D.C.: U.S. Government Printing Office, 1948. v. 3.

TAUSSIG, Michael. Folk healing and the structure of conquest in the southwest of Colombia. Journal of Latin American Lore, Los Angeles, v. 2, n. 6, 1980.

Shamanism, colonialism, and the wild man: a study in terror and healing. Chicago: University of Chicago Press, 1987.

URREA, Giraldo F;; ZAPATA, Diego 0. Vegetalismo y sistema de representaciones en el curanderismo inga-camentsa. (Pretexto para una discussion sobre las cosmovisiones prehispánicas en la sociedad contemporánea). In: LAGARRIGA, Isabel; GALINIER, Jacques; PERIN, M. (Ed.). Chamanismo en latinoamérica, una revisión conceptual. Mexico: Plaza y Valdés Editores, 1995, p. 39-68.

WAWZYNIAK, João Valentin. "Engerar": uma categoria cosmológica sobre pessoa, saúde e corpo. Ilha: Revista de Antropologia, Florianópolis, v. 2, n. 5, p. 33-55, 2003.

WHITEFORD, Michael. The forgotten ones. Gainesville, Fla.: University of Florida, Center for Latin American Studies, 1976. 